\title{
Nonunion of Spinous Process Fracture Revealed by Interscapular Crepitus: A Case Report
}

\section{W Bouaicha*, M Jlidi, S Daas, M Kharrat, MA Sbai and A Khorbi \\ Orthopedics Department, Hopital MTM Nabeul, Tunisia}

*Corresponding Author: Orthopedics Department, Hopital MTM Nabeul, Tunisia.
Received: December 28, 2020

Published: February 16, 2021

(C) All rights are reserved by $\mathbf{W}$ Bouaicha.

\section{Abstract}

Fractures of the spinous process are relatively common injuries especially in the cervical spine.

Those involving the thoracic and lumbar spine are rarely reported in literature due to very little clinical relevance and cases requiring surgical treatment are even rarer.

In this article we report the case of a symptomatic non union of a fractured spinous process of T3 treated with surgical excision of the non united fragment with good clinical results.

Keywords: Spinous Process Fracture; Non Union; Surgical Excision

\section{Introduction}

Spinous process fractures of the cervical spine are relatively common injuries in traumatized patients $[1,2]$. They usually affect less commonly the thoracic and lumbar spine [1].

Isolated, these fractures are of little clinical significance [3].

The treatment is in most cases functional, and the outcome is usually favorable. However, in some cases a persistent localized pain suggests non union of the fracture site [1,3].

\section{Case Report}

A 62-year-old male patient was a pedestrian involved in a motor vehicle accident. He was seen at the A\&E department the same day. Clinical examination revealed an open injury to his lower left leg with a Gustillo and Anderson type IIIB open fracture exposing bone and deep soft tissues. Examination of the spine revealed pain on palpation of the high thoracic spine with no bruising or abrasion. Initial plain radiographic examination showed a comminuted supra-malleolar fracture of the left tibia and fibula.
No radiologic abnormalities were detected on X-ray of the thoracic spine AP and Lateral (Figure 1).

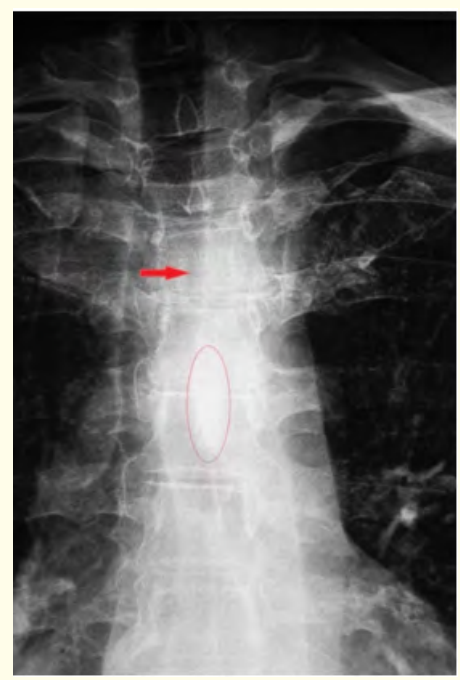

Figure 1: X-ray thoracic spine AP view showing absent spinous process (solid arrow) and "double spinous process" (ellipse). 
The patient was treated with a spanning external fixator after surgical debridement followed a week later by sural flap to cover the skin defect with good results both radiologically and clinically.

The patient came back within the framework of a medical expertise 1 year later. His main complaint was a painful crepitus at the cervico-thoracic junction. Clinical examination revealed a visible and audible "clunck" at the interscapular region.

A cervicodorsal CT examination was performed. It concluded to a non union of a displaced fracture of the spinous process of $\mathrm{T} 3$ (Figure 2).

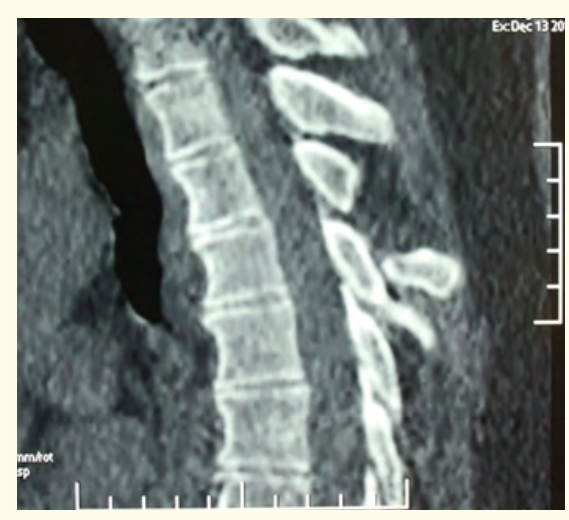

Figure 2: CT scan imaging with sagittal reconstruction.

A surgical excision of the spinous process as well as of the surrounding impinging tissues was performed with no further complications and good functional outcome.

\section{Discussion}

Fractures of spinous process are mostly seen in cervical spine injuries as well as injuries to the cervico-dorsal junction [1-3], they are considered merely a warning sign thet severe spinal injury has occurred and other vertebral fractures should be sought [2]. When isolated, they require very little attention and symptomatic treatment yields satisfactory outcome [1,3].
Etiologies of spinous process fractures can be traumatic [2,4-7], iatrogenic during surgery, neoplastic or as a fatigue fracture [8$10]$ in some professions exposed to repeated minimal stress "clay shovelers' fractures" [11].

In traumatic injuries, the fracture can be caused either by a direct posterior blow [2], or indirectly by a flexion-extension mechanism causing an avulsion fracture of the inter-spinous and supraspinous ligaments $[7,11,12]$.

Plain radiologic interpretation can be difficult because of the overlay of the scapulae on the lateral view of the high thoracic spine and the cervico-dosal junction [4]. This explains the diagnostic delay in our case. A "double spinous process" is the typical finding of a displaced spinous process fracture on the AP view $[6,7,10,13,14]$.

ACT imaging with sagittal reconstruction is the preferred examination to confirm the diagnosis, quantify the amount of displacement and detect possible associated vertebral lesions.

In the cervical spine, isolated spinous process fractures are usually treated with a cervical collar fallowed by physiotherapy $[3,15,16]$. In the thoracic and lumbar region, patients presenting with spinous process fractures are advised to rest until the pain subsides. The outcome is usually good with functional treatment, however in some rare cases symptoms made of pain and movement related crepitus can occur as in our case. Pseudoarthrosis must be considered when such symptoms are reported and further exploration must be done.

Although healing rates of these fractures are notoriously low (Matthes., et al. [13]: 3 out of 107 cases; Gershon-Cohen., et al. [12]: 7 out of 38; Jonash., et al. [17]. 30\%), very little pseudoarthrosis of spinous process fractures treated surgically have been reported in the literature [1].

Venable., et al. [10] reported on a series of 10 cases of fatigue fracture of the spinous process treated by surgical excision of the bony fragment, all of them in the cervical spine. 
Some authors emphasize the fact that surgery is never indicated in these fractures, the case that we report shows that in some symptomatic non unions, surgical excision can be done with little complications and good clinical outcome.

\section{Conclusion}

Isolated fractures of the spinous process are of a relatively common occurrence and result in non union in most cases. The vast majority of spinous process fractures pseudoarthrosis remains with very little clinical relevance that's why rigid bony union should not be the main goal of treatment. Surgical excision, however, can be advocated in symptomatic non unions with good results.

\section{Bibliography}

1. Fayyazi HA and Segal L. "Surgical excision of symptomatic lumbar spinous process pseudoarthrosis". Journal of Spinal Disorders and Techniques 17 (2004): 439-441.

2. Meyer PG., et al. "Sentinel spinous process fractures". Surgical Neurology 18 (1982): 174-178.

3. Hirsh LF., et al. "Isolated symptomatic cervical spinous process fracture requiring surgery. Case report". Journal of Neurosurgery 75 (1991): 131-133.

4. Matz SR and Reeder JD. "Spinous process fractures in a jockey: a case report". American Journal of Orthopedics 28 (1999): 365-366.

5. Niemenen R. "Fractures of spinous processes of the lower cervical spine". Annales Chirurgiae Et Gynaecologiae Fenniae 62 (1973): 328-333.

6. Baker B., et al. "Case report 688. Fractures of the spinous processes of multiple thoracic vertebrae". Skeletal Radiology 20 (1991): 463-464.

7. Cancelmo J. “Clay shoveler's fracture. A helpful diagnostic sign". American Journal of Roentgenology Radium Therapy and Nuclear Medicine 115 (1972): 540-543.

8. Connolly L., et al. "Young athletes with low back pain: skeletal scintigraphy of conditions other than pars interarticularis stress". Clinical Nuclear Medicine 29 (2004): 689-693.
9. Dellestable F., et al. "Clay-shoveler's fracture. Stress fracture of the lower cervical and upper thoracic spinous processes." Revue du rhumatisme 65 (1998): 575-82.

10. Venable JR., et al. "Stress fracture of the spinous process". JAMA 190 (1964): 881-885.

11. McKellar Hall RD. "Clay shoveler's fracture". Journal of Bone and Joint Surgery 22 (1940): 63-75.

12. Gershon-Cohen J. "Whiplash fractures of cervicodorsal spinous processes: resemblance to shoveler's fracture". JAMA 155.6 (1964): 560-561.

13. Matthes HG. "Unsere Erfahrungen bei der Schipperkrankheit". Arch OrthopUnfallchir 37 (1937): 232-245.

14. Zanca P and Lodmell EA. "Fracture of the spinous processes. A "new" for the recognition of fractures of cervical und upper dorsal spinous process". Radiology 56 (1951): 427-429.

15. Debuch L. "Die Schipperkrankheit und ihre Behandlung". Arch Orthop Unfallchir 37 (1936): 223-231.

16. Koepchen A “Über das gehäuften Auftreten der Sogennanten Schipperkrankheit bei Erdarbeitern". Dtsch Med Wochenschr 61 (1935): 1271-1273.

17. Jonasch E. "Isolierte Dorn und Querfortsatzbruche". Monatsschr Unfallheilkd 108 (1970): 123-124.

\section{Assets from publication with us}

- Prompt Acknowledgement after receiving the article

- Thorough Double blinded peer review

- Rapid Publication

- Issue of Publication Certificate

- High visibility of your Published work

Website: www.actascientific.com/

Submit Article: www.actascientific.com/submission.php Email us: editor@actascientific.com

Contact us: +919182824667 